\title{
Stable Angina Pectoris: One-Year Outcomes of Patients with Obstructive Coronary Artery Disease: Multicenter Sutdy in Dakar (Senegal)
}

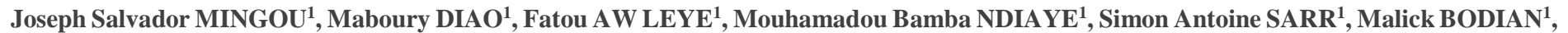
Papa Guirane NDIAYE ${ }^{1}$, Paul Coffi HESSOU ${ }^{*}$, Bouna DIACK ${ }^{3}$, Allasane MBAYE ${ }^{3}$, Aliou Alassane NGAÏDE ${ }^{3}$

${ }^{1}$ Department of Cardiology, National University Hospital Center Aristide le Dantec of Dakar; Faculty of Medicine, Pharmacy and Odontology-DAKAR (SENEGAL).

${ }^{2}$ Cheick Anta Diop University of Dakar / Doctoral School of Life Sciences, Health and Environment (ED-SEV) / Biology, Nutrition and Human Pathology.

${ }^{3}$ Department of Cardiology, Idrissa Pouye General Hospital of Dakar; Faculty of Medicine, Pharmacy and Odontology -DAKAR (SENEGAL)

*Corresponding Author: Paul Coffi HESSOU, Departments of Cardiology, Aristide le Dantec National University Hospital Center; and Idrissa Pouye General Hospital of Dakar (SENEGAL)

Received Date: October 29, 2021; Accepted Date: December 29, 2021; Published Date: January 05, 2022

Citation: Joseph S. MINGOU., Maboury DIAO, Fatou AW LEYE, Mouhamadou B. NDIAYE., Simon A. SARR., et all (2022). Stable Angina Pectoris: One-Year Outcomes of Patients with Obstructive Coronary Artery Disease: Multicenter Sutdy in Dakar (Senegal). J. Clinical Cardiology and Cardiovascular Interventions, 5(1); Doi:10.31579/2641-0419/233

Copyright: (C) 2022 Paul Coffi HESSOU, This is an open-access article distributed under the terms of the Creative Commons Attribution License, which permits unrestricted use, distribution, and reproduction in any medium, provided the original author and source are credited.

\section{Abstract}

Background: CAD management is important in prevention of disease progression. But we have very little study or research on the evolution of stable angina in amulatory patients without coronary antecedents and with obstructive coronary disease.

Purpose: The objective of our study was to analyze the clinical and angiographic profil of patients with stable chest pain and to assess their angina status one year outcomes.

Patients and methods: All patients who presented with symptomatic angina pectoris and/or signs of ischemia and first diagnosis of obstructive CAD in the Cardiology Departments of Idrissa Pouye General Hospital and Aristide Le Dantec National University Hospital Center of Dakar, from March 01, 2019 to December 31, 2020 were selected.

The clinical characteristics, initial angiographic findings, therapeutic strategy and outcome within the first year were analyzed.

Results: During the study period, 84 outpatients presenting with symptomatic stable chest pain and first obstructive coronary

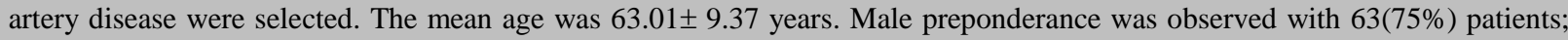
Clinical symptoms were dominated by typical pain with $46.4 \%(\mathrm{n}=39)$; the risk factors were dominated by hypertension $61.9 \%$ $(\mathrm{n}=52)$; diabetes $41.7 \%(\mathrm{n}=35)$ and dyslipidemia $33.3 \%(\mathrm{n}=28)$.

During follow-up, 10 patients $(11.90 \%)$ remained untraceable while 9 patients $(10.71 \%)$ were not available for check-up; 3 patients $(3.57 \%$ ) died during follow-up. Only 62 patients (73.80) could be evaluated; among those who were alive and controlled, 26 patients $(41.93 \%)$ with angina at baseline still had angina symptoms, 2 patients $(3.22 \%)$ had undergone myocardial infarction; one $(1.61 \%)$ had undergone urgent revascularization; one (1.61\%) patient developed heart failure. Finally 32 patients $(51.61 \%)$ were event-free and angina-free

Conclusion: The management of outpatients with stable chest pain and first obstructive CAD appears favourable, with good adherence to guideline-based therapies one year outcomes. Stable chest pain is not associated with an increased risk for adverse cardiovascular outcomes but there remains room for improvement in terms of risk factor control.

Key-words: stable angina pectoris; obstructive coronary artery disease; coronary risk factors; clinical outcome; sub-Saharan Africa 


\section{Abbreviations}

ACEI: Angiotensin Converting Enzyme Inhibitor

ARB: Angiotensin receptor blocker

CAD: Coronary artery disease

DAPT: Dual Antiplatelet Therapy

DVD: double-vessel disease

HDL-C : High-density lipoprotein cholesterol

LAD : Left artery descending

LBBB : Left bundle branch block

LCx: Left circumflex

LDL-C : Low-density lipoprotein cholesterol

LVEF : Left ventricular ejection fraction

LMCA: Left main coronary artery

MACE: Major adverse cardiac events

PCI: Percutaneous coronary intervention

RBBB : Right bundle branch block

RCA: Right coronary artery

STEMI: ST-Elevation Myocardial Infarction

SVD: Single-vessel disease

TVD: Three-vessel disease

\section{Introduction}

Stable angina pectoris is defined as episodes of chest pain precipitated by physiologic situations of increased oxygen demands to the heart. It occurs most commonly during or immediately after exercise. Indeed stable angina is characterized by chest discomfort or angina equivalent that is provoked with exertion and alleviated at rest or with nitroglycerin $[1,2]$. This is often one of the first manifestations or warning signs of underlying coronary disease. Therefore the recognition and appropriate management of stable angina is critical in reducing the risks of future complications [3]. The most important complication of stable angina is the possibility of progression to acute coronary syndrome. Stable angina is also associated with an average annual risk of $3 \%$ to $4 \%$ for myocardial infarction or death [4].

As outlined in Societies of Cardiology guidelines, management strategies include lifestyle modification, risk factor reduction, pharmacological, and invasive management if significant obstructive CAD is present [1]. Several studies have explored the prognostic impact of stable angina in patients with $\mathrm{CAD}[5,6,7,8]$.

Lifelong treatment and monitoring are required in patients with coronary artery disease. The clinical course of these patients may be benign over time but also fraught with cardiovascular complications that can be treated during follow-up.

This study was, therefore, aimed to evaluate the clinical and coronary angiographic profile of outpatients with symptomatic stable chest pain and first obstructive $\mathrm{CAD}$, their treatment, and to assess one-year outcomes.

\section{Patients and Method}

\section{2-1. Study design and patients}

This was an observational, descriptive, and analytical study conducted from March 1, 2019 to October 31, 2021, in Cardiology Departments of General Hospital Idrissa Pouye and Aristide Le Dantec National University Hospital Center of Dakar.

We had included in our study all outpatients with symptomatic stable angina or ischemic equivalent (dyspnea, palpitations, blockpnea ...) after non-invasive test and who had significant coronary lesions at coronary angiography. All patients with known coronary artery disease (history of STEMI, PCI, and coronary artery bypass surgery) were excluded.

\section{2-2. Baseline characteristics of study population}

Information on demographic characteristics, cardiovascular risk factors, symptoms, and noninvasive test results was collected before coronary angiography was performed. Some patients had been contacted for additional information. Hypertension was defined as a systolic blood pressure $\geq 140 \mathrm{mmHg}$ and/or a diastolic blood pressure $\geq 90 \mathrm{mmHg}$; diabetes was defined as chronic hyperglycemia. It is confirmed if the fasting blood glucose level is $\geq 1.26 \mathrm{~g} / 1$ during two successive tests; Hypercholesterolemia was defined by a total cholesterol $>2 \mathrm{~g} / \mathrm{l}$, an HDLcholesterol $<0.40 \mathrm{~g} / \mathrm{l}$, or an LDL-cholesterol > $1.6 \mathrm{~g} / 1$; Obesity was defined by a body mass index $(\mathrm{BMI})>30 \mathrm{~kg} / \mathrm{m}^{2}$; normal weight $18-24,9$ $\mathrm{kg} / \mathrm{m}^{2}$ and overweight, $25-29 \mathrm{~kg} / \mathrm{m}^{2}$

The presence of angina was recorded at baseline and annual check-up, and was defined as chest pain during physical exertion or equivalent symptoms necessitating occasional or permanent use of antianginal drugs in the judgment of the cardiologist.

Symptoms were classified as typical angina, atypical chest pain, ischemic equivalent, or no symptoms. Typical angina was defined as [1] chest pain or substernal discomfort that is [2] caused by exertion or emotional stress and [3] relieved by rest and/or nitroglycerin. Atypical chest pain included patients with atypical angina (only two of the above criteria) and those with non-angina chest pain (one or none of the above criteria). Ischemic equivalents were considered any collection of clinical signs (dyspnea, dizziness, arrhythmias, blockpnea).

The suspicion of CAD was based on the presence and characteristics of chest pain symptoms and the presence of noninvasive test results (ECG, Exercise ECG, Echocardiography, and Stress Echocardiography).

We assessed the left ventricular ejection fraction by the Simpson biplane method. It was considered normal for values above $50 \%$.

\section{2-3. Assessment of angiographic CAD}

All patients underwent coronary angiography according to the standard Judkin's technique. Coronary angiography was performed through the femoral or radial approach and coronary was assessed in multiple projections by two experienced operators. Angiographic findings were collected from the electronic coronary angiography report.

The severity of coronary lesions was assessed by the degree of stenosis (the percentage reduction of the arterial lumen): In our study we have considered Non-significant lesions as stenosis < 50\%; significant lesions for stenosis between $50-70 \%$; tight lesions: stenosis between $70-90 \%$ and more; Occlusions and sub-occlusions.

To assess the consequences of angina evolution on cardiovascular outcomes, patients were categorized into 3 groups according to the evolution of angina between baseline and 1 year: persistence, complications and disappearance.

Predefined endpoints for angina progression included symptoms, results of noninvasive tests at 1 year (ECG, echocardiography, stress echocardiography) and major adverse cardiac events (all-cause mortality, 
nonfatal myocardial infarction, unstable angina hospitalization or revascularization, heart failure hospitalization, and cerebrovascular event) at subsequent follow-up.

\section{2-4. Statistical analysis}

All variables in study were entered in SPSS version 16 for windows statistical software and analyzed; Descriptive statistics were generated with percentages for discrete variables; means and standard deviations for continuous variables. The Chi-square test was used and considered significant for $p<0.05$.

\section{2-5. Ethical aspects}

The study was done in accordance with the Declaration of Helsinki. All patients who agreed to participate had given their consent freely. Furthermore, according to the protocol in our cardiology departments, patients gave always written informed consent before the different diagnostic tests.

This study was also approved by the Research Ethics Committee (REC) of the Cheikh Anta Diop University of Dakar (Protocol Number 0407/2019/CER/UCAD).

\section{Results}

\section{3-1. Demographic and clinical characteristics}

During the study period, 1137 patients were admitted in both department of Cardiology for coronary angiography. Of these, 143 were suspected for stable angina pectoris; 59 patients $(41.26 \%)$ had normal coronaries while 84 patients $(59.74 \%$ ) had significant lesions of CAD and constituted the study group.

The baseline clinical characteristics of patients are given in table 1 . There was a male preponderance with 63 patients (75\%); the mean age was
$63.01 \pm 9.37$ years, with extremes of 31 and 81 years. The most representative age ranges was [60-69 [years with 38 patients $(45.24 \%)$.

\begin{tabular}{|c|c|c|c|}
\hline \multicolumn{2}{|c|}{ Risk factors of CAD } & $(n=84)$ & $(\%)$ \\
\hline \multicolumn{4}{|c|}{ Age (mean, years) $\quad 63.01 \pm 9.10$} \\
\hline \multicolumn{2}{|l|}{ Male } & 63 & 75 \\
\hline \multicolumn{2}{|l|}{ Female } & 21 & 25 \\
\hline \multicolumn{2}{|l|}{ Hypertension } & 52 & 61.9 \\
\hline \multicolumn{2}{|l|}{ Diabetes } & 35 & 41.7 \\
\hline \multicolumn{2}{|l|}{ Dyslipidemia } & 28 & 33.3 \\
\hline \multirow{3}{*}{$\begin{array}{l}\text { Body mass } \\
\text { index }\left(\mathrm{kg} / \mathrm{m}^{2}\right)\end{array}$} & Normal weight & 71 & 84.52 \\
\hline & overweight & 5 & 5.95 \\
\hline & Obesity & 8 & $9.52 \%$ \\
\hline \multicolumn{2}{|c|}{ Physical inactivity } & 23 & 27.4 \\
\hline \multicolumn{2}{|l|}{ Smoking } & 5 & 5.95 \\
\hline \multicolumn{2}{|l|}{ Hyperuricemia } & 1 & 1.2 \\
\hline \multicolumn{2}{|l|}{ Family history } & 1 & 1.2 \\
\hline \multicolumn{2}{|c|}{ Typical chest pain } & 39 & 46.4 \\
\hline \multicolumn{2}{|c|}{ Atypical chest pain } & 37 & 44 \\
\hline \multicolumn{2}{|c|}{ Dyspnoea } & 7 & 8.3 \\
\hline \multicolumn{2}{|c|}{ Dyspnea and atypical chest pain } & 1 & 1.2 \\
\hline
\end{tabular}

Table 1: Baseline characteristics of study population

Clinical symptoms were dominated by typical pain, 46.4\% (n=39); 7 patients $(8.3 \%)$ had presented with dyspnoea. There were not significative difference between both symptoms following the number of disease vessels $(\mathrm{p}=0.07)$.

The prevalence of hypertension was $61.9 \%(n=52)$; diabetes was $41.7 \%$ $(n=35)$; dyslipidemia was $33.3 \%(n=28)$. The table 2 shows the biological parameters of study population.

\begin{tabular}{|l|c|c|}
\hline Parameters & Mean/standard-deviation & Extreme values \\
\hline Hematocrit $(\%)$ & $41.97 \pm 4.97$ & $29-58.30$ \\
\hline Blood platelet /mm3 & $292345 \pm 71700$ & $116000-461000$ \\
\hline Hemoglobin $(\mathrm{g} / \mathrm{L})$ & $13,31 \pm 1.31$ & $9.40-15.90$ \\
\hline Creatinine $(\mathrm{mg} / \mathrm{L})$ & $11.64 \pm 2.61$ & $6.5-23$ \\
\hline Urea $(\mathrm{g} / \mathrm{L})$ & $0.31 \pm 0.10$ & $0.10-0.84$ \\
\hline Glycemia $(\mathrm{g} / \mathrm{L})$ & $1.08 \pm 0.36$ & $0.64-2.56$ \\
\hline Triglyceridaemia $(\mathrm{g} / \mathrm{L})$ & $1.13 \pm 0.59$ & $0.45-3.39$ \\
\hline LDL-C $(\mathrm{g} / \mathrm{L})$ & $1.39 \pm 0.41$ & $0.34-2.27$ \\
\hline HDL-C $(\mathrm{g} / \mathrm{L})$ & $0.48 \pm 0.16$ & $0.11-1.04$ \\
\hline Total Cholesterol $(\mathrm{g} / \mathrm{L})$ & $2.04 \pm 0.52$ & $0.80-3.44$ \\
\hline
\end{tabular}

Table 2: Biological characteristics of study population

In our study, at least one noninvasive test was performed in all patients. These tests were mainly resting Electrocardiogram and resting echocardiography with $100 \%(n=84)$ and $86.9 \%(n=73)$ respectively.

On electrocardiogram, repolarization disorders were dominated by ST segment sub-shift and negative $\mathrm{T}$ waves with $17.92 \%(\mathrm{n}=15)$ and $25 \%$ $(\mathrm{n}=21)$ respectively.

Abnormalities of the systolic function of the left ventricle with an Ejection Fraction $<50 \%$ and disorders of the segmental kinetics were observed in $14(16.7 \%)$ and $17(20.12 \%)$ patients respectively.

\section{3-2. Angiographic characteristics}

Coronary angiography revealed that 27 patients $(32.14 \%)$ had singlevessel; 28 patients $(33.33 \%)$ had double vessel disease; and 29 patients $(34.52 \%)$ had triple vessel disease. The right radial approach was the most used with $84.52 \%(n=71)$. Coronary angiography revealed 324 coronary lesions. According to the degree of coronary artery obstruction, tight lesions were the most important with $48.14 \% \quad(n=156)$ followed by significant lesions with $23.14 \%(n=75)$.

Amongst the vessels involvement the most common was the left anterior descending (LAD) with $39.20 \%(n=127)$, followed by the right coronary artery (RCA), $28.08 \%(n=91)$ and the Left Circumflex $(\mathrm{LCx}) 25 \%(\mathrm{n}=81)$. All angiographic findings are summarized in table 3. 


\begin{tabular}{|l|c|c|}
\hline Coronary angiography approach & $\mathbf{N}=\mathbf{8 4}$ & \% \\
\hline Right radial & 71 & 84.52 \\
\hline Right femoral & 6 & 7.14 \\
\hline Left femoral & 7 & 8.34 \\
\hline Number of disease vessels & 27 & 32.14 \\
\hline Single-vessel disease & 28 & 33.34 \\
\hline Double-vessel disease & 29 & 34.52 \\
\hline Three-vessel disease & 19 & 5.86 \\
\hline Localization of the lesion on coronary arteries (N=324) \\
\hline Left main( LM) & 127 & 39.20 \\
\hline Left anterior descending (LAD) & 81 & 25 \\
\hline Left circumflex (LCx) & 6 & 1.85 \\
\hline Intermedius raphius & 91 & 28.08 \\
\hline Right coronary artery (RCA) & 46 & 14.20 \\
\hline Distribution of lesions according to the degree of arteries obstruction \\
\hline Non significant lesions (stenosis <50\%) & 75 & 23.15 \\
\hline Significant lesions (stenosis 50-70\%) & 156 & 48.14 \\
\hline Tight lesions ( stenosis 70- 90\% and more) & 47 & 14.51 \\
\hline Occlusion and / or subocclusion
\end{tabular}

Table 3: Angiographic findings of study population

Out of the 84 patients with obstructive coronary artery disease, 37 patients $(44.05 \%)$ had recommended for angioplasty, and 47 patients $(55.95 \%)$ for medical management only.

The number of angioplasties performed was 43. The procedure were mostly related to LAD and RCA with $57.14 \%(n=25)$ and $30.95 \%(n=13)$ respectively. The direct stenting technique was used in $45.24 \%(\mathrm{n}=19)$ of cases. Active stents were used in the majority of cases with $80.95 \%$ $(n=35)$. There were no major incidents during the procedures. However, we noted one [1] patient with defective desobtruction of the right coronary and one patient [1] had the right coronary ostium dissection. There was no death during the procedure.

\begin{tabular}{|c|c|c|}
\hline \multirow{5}{*}{$\begin{array}{l}\text { Artery involved in } \\
\text { angioplasty }\end{array}$} & Left artery descending & $25(58.14)$ \\
\hline & Right coronary artery & $13(30.23)$ \\
\hline & Intermedius raphius & $2(4.66)$ \\
\hline & Circumflex & $2(4.66)$ \\
\hline & Left main & $1(2.33)$ \\
\hline \multirow[b]{2}{*}{ Stent type } & Bare-metal stent & $7(16.67)$ \\
\hline & Active stent & $35(83.33)$ \\
\hline \multirow[b]{2}{*}{ Method used } & Predilatation & $23(54.76)$ \\
\hline & Stenting direct & $19(45.24)$ \\
\hline \multirow[b]{2}{*}{ Results } & Success & $42(97.67)$ \\
\hline & Fail & $1(2.33)$ \\
\hline \multirow[b]{2}{*}{ Incident } & Coronary artery dissection & $1(2.33)$ \\
\hline & Coronary artery desobstruction failure & $1(2.33)$ \\
\hline \multicolumn{3}{|l|}{ Optimal medical treatment } \\
\hline Acetylsacyclic & & $76(90.48)$ \\
\hline B- blockers & & $75(89.50)$ \\
\hline ACEI/ ARB & & $64(76.20)$ \\
\hline Statin & & $58(69.05)$ \\
\hline 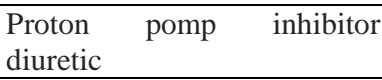 & & $46(54.76)$ \\
\hline Calcium channel blocker & & $47(55.95)$ \\
\hline DAPT & & $39(46.23)$ \\
\hline Nitrate & & $33(69.28)$ \\
\hline P 2 Y receptor inhibitor & & $30(35.71)$ \\
\hline Oral anticoagulants & & $24(28.57)$ \\
\hline Other antianginal drug & & $21(25)$ \\
\hline
\end{tabular}

ACEI: Angiotensin Converting Enzyme Inhibitor; ARB: Angiotensin receptor blocker; DAPT: Dual Antiplatelet Therapy

The table 4 summarizes the characteristics of angioplasty and medical treatment. Aspirin was the most frequently used drug $(90.48 \%$ of patients); Dual antiplatelet therapy (DAPT) was used in $46.23 \%$ of patients. The use of lipid-lowering drugs was also high overall, with a significantly frequent rate $(69.05 \%)$, whereas angiotensin-converting enzyme inhibitors (ACEI) or angiotensin II receptor blockers (ARB) were used more frequently $(76.20 \%)$; Ninety-one point sixty-seven percent patients $(89.5 \%)$ were taking beta blockers. Only $55.95 \%$ of patients took calcium antagonists, whereas use of other antianginal drugs $(25 \%)$ and oral anticoagulants $(28.57 \%)$ was lower. 


\section{3-3.One-year outcomes of patients with obstructive coronary artery disease}

During follow-up, $10(11.90 \%)$ patients remained untraceable while 9 $(10.71 \%)$ were not available for check-up; $3(3.57 \%)$ patients died during follow-up. Only 62 (73.80) patients could be evaluated; among those who were alive and controlled, 26(41.93\%) with angina at baseline still had angina symptoms, $2(3.22 \%)$ had undergone myocardial infarction; one $(1.61 \%)$ had undergone urgent revascularization; one $(1.61 \%)$ patient developed heart failure. Only $32(51.61 \%)$ patients were event-free and angina-free. These findings are summarized in figure $\mathbf{1}$.

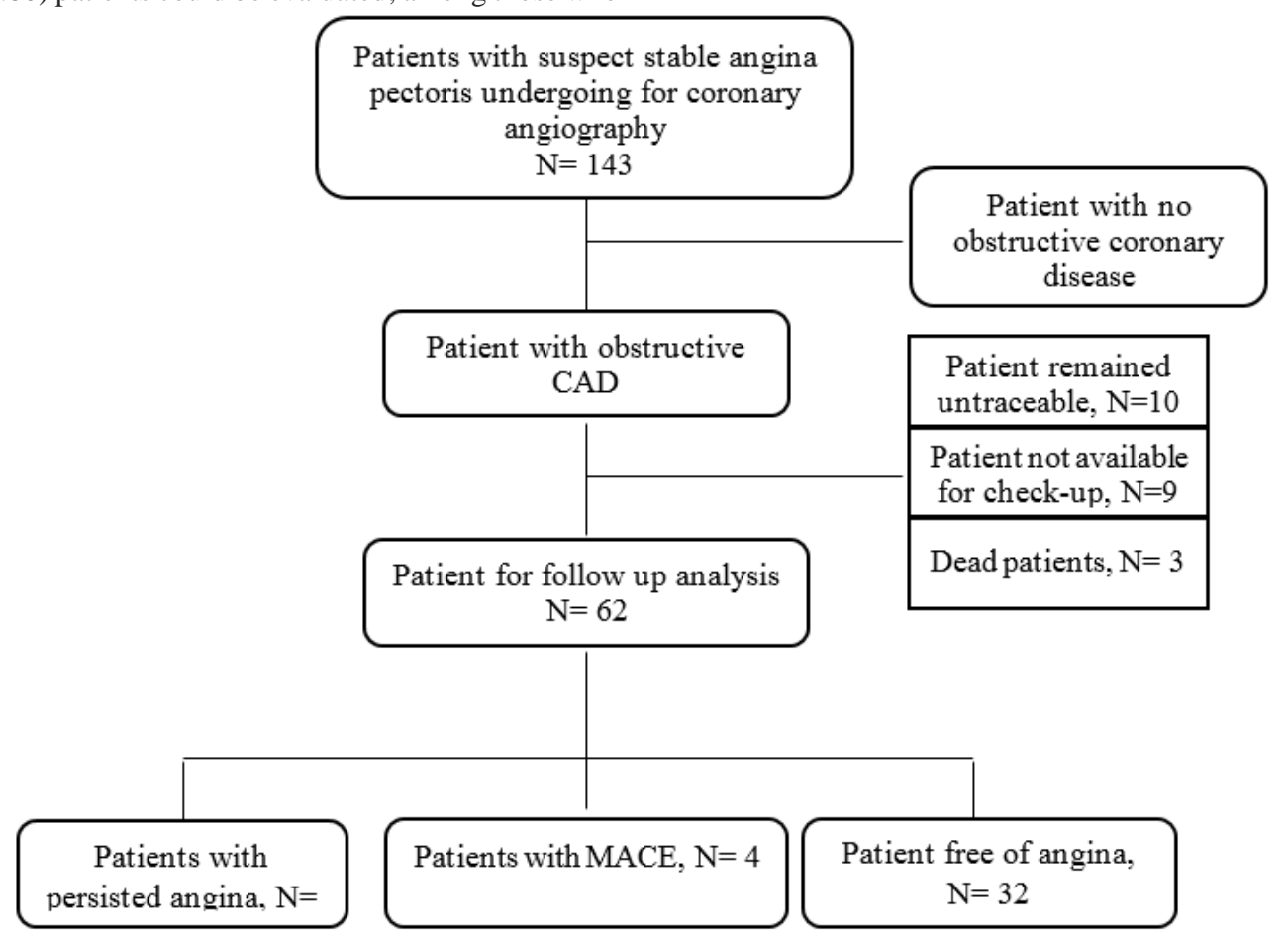

Figure 1: Flowchart of the study showing inclusion of patients and follow-up results

\section{Discussion}

This study showed that patients with stable chest pain and obstructive CAD were older and predominantly male. This finding was consistent with other studies results but with and advanced age in certain study populations [9, 10]. This shows that the onset of stable angina with obstructive coronary artery disease in sub-Saharan African is early. This disparity could be explained on the one hand by the much higher life expectancy in these countries. On the other hand, the low awareness of the population on the relationship between lifestyle and cardiorespiratory diseases could be another explanatory factor of this difference.

In the current study we further tried to elucidate the risk factors. Among our patients the most prevalent risk factors associated to obstructive CAD were hypertension, diabetes, dyslipidemia and physical inactivity. Although these patients constituted a heterogeneous group, modifiable risk factors frequencies were important and suggested the need for heightened efforts for preventive strategies in our study cohort. The low proportion observed for smoking in our study could be explained by cultural and religious constraints which would influence massive consumption.

Typical angina and atypical were the most important symptom observed; however there were not significative difference between both symptoms following the number of diseased vessels.

Coronary angiography revealed that 27 patients $(32.14 \%)$ had singlevessel; 28 (33.33\%) patients had double vessel disease; and 29 (34.52\%) patients had triple vessel disease. The literature does not provide any specific data on the coronary status of the patient with stable angina.
The right radial approach was the most used for coronary angiography with $84.52 \%(\mathrm{n}=71)$. This approach has the advantage of reducing haemorrhagic complications as observed in the RIVAL study [11] and overall mortality according to the MATRIX study [12].

In our study $62(73.80 \%)$ patients were recommended for angioplasty. Only $37(59.68 \%)$ had done it. This is due to the high cost of this procedure in relation to the limited resources of the patients and also to the lack of systematic health coverage for this kind of therapeutic invasive procedure.

The majority of patients $(83.33 \%)$ had received an active stent as recommended in the guidelines $[13,14]$. Active stents, compared to baremetal stents, bring a decrease in the rate of restenosis and new revascularization procedures, but without a decrease in death or myocardial infarction. The direct stenting technique performed in $45.24 \%$. The advantage of direct stenting is to reduce the procedure time, the amount of contrast injected, the radiation time and the cost. Overs investigators further notes that direct stenting would reduce the periprocedural mortality rate [15]. Our success rate was $97.67 \%$, similar to the rates reported in the literature [16]. These success rates are related to both accumulated experience and technical progress.

In patients with stable coronary syndromes revascularization reduces cardiovascular death and MI compared with conservative treatment. In our study revascularization was performed in $44.27 \%$ of patients but we did not observe a significant difference in angina status between these patients and those who received optimal medical treatment.

However, controversy exists over the benefit of revascularization in patients with chronic stable CAD compared with medical management 
$[17,18]$. Results from the COURAGE study implicated that PCI did not reduce risk of death, MI and other cardiovascular events when added to current medical treatment in patients with stable CAD [19]. In contrast, a large meta-analysis resulted in a benefit of revascularization. The positive effects of revascularization are clearly shown in patients with angina symptoms. In these cases, PCI or CABG more effectively relieve angina, reduce treatment with anti-angina drugs as well as improve physical resilience and quality of life $[4,20]$. In this context, the latest ESC guidelines recommend revascularization on the basis of the presence of significant coronary artery stenosis, the severity of ischemia and the expected benefit for prognosis [1]. Indeed, the individual benefit/risk ratio must always be evaluated and revascularization considered only if its expected benefit outweighs its potential risk [1,4].

The goals of management of stable angina due to obstructive CAD are to reduce symptoms and prevent future adverse events [1, 3]. Our study shows a low rate of MACE and mortality while disappearance of angina was observed in 51,62\%. Several studies have explored the prognostic impact of stable angina in patients with $\operatorname{CAD}[5,6,7,8,21,22]$. In the Multinational CLARIFY Study, among 7212 (22.1\%) patients who reported angina at baseline, angina disappeared (without coronary revascularization) in $39.6 \%$ at 1 year [5].

Our results were different with those observed in these studies. The discrepancy in outcomes might be explained by differences in inclusion criteria, adverse outcome definitions, different methodology and length of follow-up time.

\section{Conclusion}

In our study population the management of outpatients with symptomatic chest pain and first obstructive CAD appears favourable, with good adherence to guideline-based therapies one year outcomes. Stable chest pain is not associated with an increased risk for adverse cardiovascular outcomes but there remains room for improvement in terms of risk factor control.

\section{Limitations of the Study}

The study cohort was relatively small, especially the patient population with angina symptoms and obstructive coronary artery disease; $22.62 \%$ of patients were lost to follow-up. Thus, for a better understanding of the management and outcome of stable CAD in Sub-Saharan population, studies with larger numbers of patients are needed.

In addition we did not repeat the analysis of cardiovascular risk factors after the follow-up period. This would have made it possible to assess the effect of treatment on modifiable risk factors.

Declaration of interest: the authors declare that they have no interest.

\section{References}

1. Knuuti J, Wijns W, Saraste A, et al. ESC Scientific Document Group, 2019 ESC Guidelines for the diagnosis and management of chronic coronary syndromes: The Task Force for the diagnosis and management of chronic coronary syndromes of the European Society of Cardiology (ESC), Eur Heart Journal 2020; 41(3):407477.

2. Ford TJ, Collin B. Angina contemporary diagnosis and management. Heart 2020; 106 (5):387-398.

3. Parvard M, Rayer-Harley E, Sedllak et al. Recents Developpments in sex-related differences in Presentation, Prognosis and Managment of Coronary Artery Disease. Canadian Journal of Cardiology, 2018; 34(4): 390-399.
4. Joshi PH, de Lemos JA. Diagnosis and Management of Stable Angina: A Review. JAMA. 2021;325(17):1765-1778. doi:10.1001/jama.2021.1527.

5. Mesnier J, Ducrocq G, Danchin $\mathrm{N}$ et al. International Observational Analysis of Evolution and Outcomes of Chronic Stable Angina. The Multinational CLARIFY Study, Circulation 2021; 144: 512-523.

6. Felicita Andreotti, Filippo Crea, Udo Sechtem, Diagnosis and outcomes in patients with suspected angina: what are they trying to tell us?, European Heart Journal, Volume 40 (18); 1436-1439.

7. Therming $\mathrm{C}$, Galatius S, Heitmann $\mathrm{M}$ et al. Low diagnostic yield of noninvasive testing in patients with suspected coronary artery disease: result from a large unselected hospital based sample ESCQuality of care and Clinical outcomes 2018; 4: 301-308

8. Reeh J, Therming CB, Heitmann M. et al. Prediction of obstructive coronary artery disease and prognosis in patients with suspected stable angina. Eur Heart J 2018; 40:1426-1435.

9. Westermann D, Savvatis K, Wollenberg U. et al. Prevalence of Obstructive Coronary Artery Disease in Ambulatory Patients with Stable Angina Pectoris. J Clin Exp Cardiolog 6: 2015; 387

10. Nakas G, Bechlioulis A, Marini A et al. The importance of characteristics of angina symptoms for the prediction of coronary artery disease in a cohort of stable patients in the modern era Hellenic Journal of Cardiology (2019) 241-246.

11. Jolly SS, Yusuf S, Cairns J et al. Radial versus femoral access for coronary angiography and intervention in patients with acute coronary syndromes (RIVAL): a randomised, parallel group, multicentre trial. Lancet 2011; 377:1409-1420.

12. Borja I, Stefan J, Stefan A et al. ESC Guidelines for the management of acute myocardial infarction in patients presenting with ST-segment elevation. The Task Force for the management of acute myocardial infarction in patients presenting with STsegment elevation of the European Society of Cardiology (ESC). Eur Heart J 2017;00:1-66.

13. Piccolo R, Bonaa KH, Efthimiou O et al. Drug-eluting stents or baremetal stents for PCI: asystematic review and individual patient data meta-analysis of randomised clinical trials. Lancet 2019; 393: 2503-2610.

14. Isik T, Ayhan E, Uyarel $\mathrm{H}$ et al. A comparison of direct versus conventional stenting in patients undergoing primary angioplasty for ST-elevation myocardial infarction. Coron Artery Dis 2012; 23 (5) :348-353.

15. Piper WD, Malenka DJ, Ryan TJ et al. Predicting vascular complications in percutaneous coronary interventions. Am Heart J 2003; 145:1022-1029.

16. New York State Department of Health. August 2012. Percutaneous Coronary Interventions (PCI) in New York State 2008-2010.

17. Simoons ML, Windecker S. Chronic stable coronary artery disease: drugs vs. revascularization. Eur Heart J. 2010; 31:530541.

18. Hochmann JS, Steg PG. Does preventive PCI work? N Engl J Med. 2007; 356:1572-1574.

19. Boden WE, O'Rourke RA, Teo KK, Hartigan PM, Maron DJ, Kostuk WJ, Knudtson M, Dada M, Casperson P, Harris CL, Chaitman BR, Shaw L, Gosselin G, Nawaz S, Title LM, Gau G, Blaustein AS, Booth DC, Bates ER, Spertus JA, Berman DS, Mancini GBJ, Weintraub WS, for the COURAGE Trial Research Group. Optimal medical therapy with or without PCI for stable coronary disease. N Engl J Med. 2007;356:1503-1516.

20. Mukherjee D, Moliterno DJ. Effectiveness of PCI for non acute coronary artery disease. Lancet. 2009; 373:870-872.

21. Lang IM, Badr-Eslam R, Greenlaw N, Young R, Steg PG. Management and clinical outcome of stable coronary artery 
disease in Austria : Results from 5 years of the CLARIFY registry. Wien Klin Wochenschr. 2017; 129(23-24):879-892. Doi:10.1007/s00508-017-1248-1241

22. Danchin N, Ferrieres J, Guenoun M, Cattan S, Rushton-Smith SK, Greenlaw N, Ferrari R, Steg PG; CLARIFY Investigators. Management of outpatients in France with stable coronary artery disease. Findings from the prospeCtive observational LongitudinAl RegIstry oF patients with stable coronary arterY disease (CLARIFY) registry. Arch Cardiovasc Dis. 2014 AugSep; 107(8-9):452-61. Doi: 10.1016/j.acvd.2014.06.001. Epub 2014 Aug 13. PMID: 25128934.
This work is licensed under Creative Commons Attribution 4.0 License

To Submit Your Article Click Here:

Submit Manuscript

DOI: $10.31579 / 2641-0419 / 233$
Ready to submit your research? Choose Auctores and benefit from:

$>$ fast, convenient online submission

$>$ rigorous peer review by experienced research in your field

$>$ rapid publication on acceptance

$>$ authors retain copyrights

$>$ unique DOI for all articles

$>$ immediate, unrestricted online access

At Auctores, research is always in progress.

Learn more https://auctoresonline.org/journals/clinical-cardiology-andcardiovascular-interventions 